\title{
Józef Dąbrowski
}

Sieć Badawcza Łukasiewicz - Instytut

Elektrotechniki, Warszawa

jozef.dabrowski@iel.lukasiewicz.gov.pl

DOI: 10.35117/A_ENG_21_05_01

\section{Possible electrochemical corrosion of rails on a railway track electrified with direct current}

\begin{abstract}
The article describes the construction of a railway line electrified with direct current. Attention is paid to the isolation of the elements leading to the traction current in the supply and return network, and to the difference in significance of these insulations. The reasons for the occurrence of stray currents and their nature in any cross-section of the track on the trail are given. The necessary conditions for the disclosure of electrochemical processes on the rails of the track tracks were shown. It has been shown that the galvanization processes occur locally on the trail - the application of soil electrolyte ions on the surface of the rails and electrochemical corrosion - the loss of the rails material. During the movement of electrified trains on the route, moisture is necessary and the contact of the rails with the poorly drained support of the foot or with the ballast - track ballast.
\end{abstract}

Keywords: Electrified railway route; Stray currents; Electrochemical corrosion

\section{Introduction}

An electrified railway track is characterized by the fact that a contact wire is suspended above the track rails. It is an overhead network that supplies the vehicle with electricity. The contact wire above the trail tracks is suspended in a zigzag so that the contact surface of the current collector wears evenly along its entire active length and width. Traction poles placed outside the tracks in double-track lines are used for suspending the cable. The cable is suspended at a variable distance from the following poles on outriggers protruding from the poles at appropriate heights, which ensures the required height above the railhead and a zigzag system above the tracks. Additionally, in order to obtain a stable position of the cable and smooth operation of the sliding contact, regardless of the air temperature conditions, strainers/cable strainers are used to suspend every number of poles depending on the route profile. Both the points supporting the cable and its tension must meet the requirements of electrical insulation. In the space between the traction poles, the insulation is provided by air - the height of the suspension above the ground. In general, section insulators - breaks in the metallic continuity of the contact wire - occur every $20 \mathrm{~km}$ on the railway line. On both sides of this insulator, power cables coming from the traction substation are connected via disconnectors. In doubletrack lines, each contact wire above the tracks has its own sectional insulator and cable connections from the same substation. On both sides of this connection, there are adjacent substations, enabling the individual two-sided power supply to each of these approximately 20 $\mathrm{km}$ sections. This division ensures the possibility of applying selective protections for individual sections of the upper network and carrying out inspections or repairs of sections separated from the operation and disconnected from traction voltage. In railway substations, alternating current electricity from the national power system is converted into direct current energy with a nominal voltage of $3 \mathrm{kV}$. For this transformation, a set of a three-winding rectifier transformer with an appropriately selected 6 or 12-pulse diode rectifier is used. At PKP plus, the rectifier is led out to the overhead network through the DC switching station, and the minus is connected to the rails through the return cable cabinet. Therefore, at the level 
of the traction substation, the cables connected to the track rails are called return cables. In Poland, the railway tracks on the tracks are of classic ballast construction, where the rails are attached to the sleepers, which are embedded in the ballast. In the case of tracks, the insulation of the rails from the subgrade and further to the ground should be provided by support and attachment of the rail foot to the sleeper. Between the sleepers, the rail material should not touch the crushed stone.

\section{SRK systems and power supply}

The weight of the trains and their travel speeds with relatively low coefficients of friction between the wheel rims and the railhead contribute to long braking distances. For this reason, in order to ensure the safe running of railway sets, their movement along the route is organized with an appropriate distance between trains traveling on one track in a given direction. Railway Traffic Control systems (Trains - on the subway in Warsaw) are used for this. The idea behind the SRK systems is to determine the occupancy of the track section on which the train is located and to signal the admission to the given section of the next train. Movement on the train tracks should cause the next section of the track to be occupied and the section where the train left the train to be released from being occupied. Between two sections of the track occupied by two different trains in a given direction, there should be at least one section free from the train, and the signaling of the SRK should ensure the activation of the train braking system. To ensure the capacity and safety of traffic, SRK is not the only system that triggers train braking. At the initial stage of development, the SRK system used the rails of a given track in the manner shown in Figure 1.
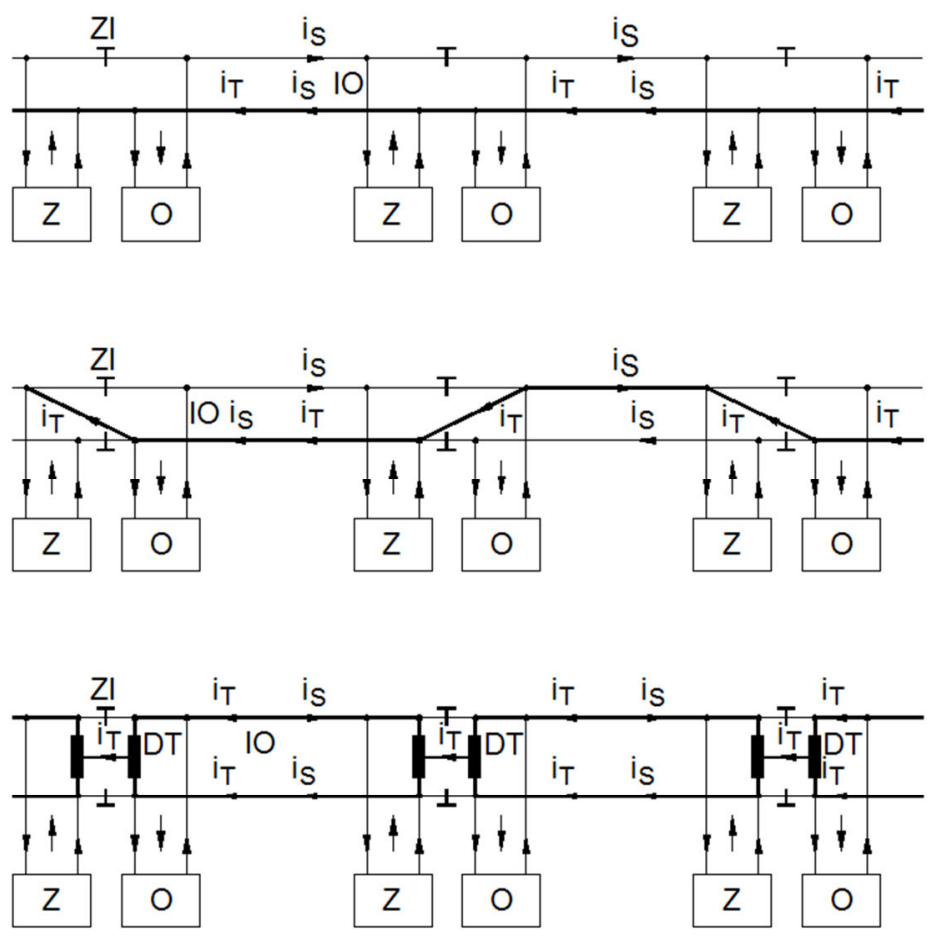

1. Simplified circuit diagrams

Markings: a) single-track insulation, single-track traction current flow, b) double-track insulation, single-track traction current flow, c) double-track insulation, two-track traction current flow, Z - power supply, O - receiver, ZI - insulated connector, IO - insulated section, DT - track choke, iS - signal current, iT - traction current. 
Fig. 1 shows diagrams of the track circuits used. The use of the power supply and receiver in track circuits in sections of rails sectioned with an insulating joint provides information about the condition of each section of the track circuit. In practice, there were three solutions: a) - single-circuit insulation and b) - double-circuit insulation with the singlecircuit flow of traction current; c) - double-circuit insulation with the two-circuit flow of traction current. In each of these solutions, the axes of the train located above the track circuit short-circuit in cases a and b longitudinally and transversely, and in the case of c transversely insulating joints, thus changing the load of sources and energy supplied to consumers in this track circuit. If the receiver is a relay coil with a ferromagnetic circuit of an electromagnet, then a change of the energy supplied from the source of energy causes a change in the energy in the coil and with appropriately selected parameters of the entire track circuit in relation to the relay coil, the position of the electromagnet armature and the working contacts of the relay mechanically coupled with it are changed. The contacts of this relay operate in other electric circuits, electrically separated from the overhead contact line, used for signaling, control, or visualization, and change their operating status when the train enters the separated track section or leaves this section to which the given receiver - relay corresponds.

At the Polish State Railways, the SRK system from Fig. 1c is replaced with axle counters. Instead of a pair of track chokes and insulating joints, a device called an axle counter is mounted to the rail in both rails. Each rim over the counter activates a sequence of signals in the counter, which can be used to determine the linear speed of the wheel rim movement over the counter, the direction, and, most importantly, one axle. The number of these axles entering the counter must agree with the number on the previous counter, and after the distance has been traveled on the next counter. In this way, the axle package corresponding to a given composition moves along the track, occupying and releasing subsequent sections. Between individual parcels, there must be a permissible time sequence of the break, also depending on the speed of movement of these trains.

\section{Notes on the track}

The construction of the trackbed and the use of rails with a specific unit weight are to ensure the durability of the track with the permissible axle loads of railway vehicles. The choice of the rail type determines the specific longitudinal resistance resulting from the use of iron on the rails. The heavier the rail, the lower the resistance. The use of SRK in the form of track circuits from Fig. 1 in each case increases the resultant longitudinal resistance of the track because the cables connecting the track choke coils and the connection of the centers of these coils are also characterized by resistances. Additionally, the material contacts of lines and rails appear, which also cause the resultant longitudinal resistance of the track to increase. Track circuits provide a specific diagnosis of rail cracks and defects in longitudinal rail connectors in the times of mechanical joining of rail sections with steel slates. In the case of axle counters in the track, the track resistance does not increase, but there is no longer any diagnosis of cracks in the rails resulting from the imposed alternating current, while it is the SRK solution that allows the use of the recommended rail-track and track-to-track connectors in the standard [1], and in the standard [2] only mentioned as a link that can limit the effect of stray currents from an electrified DC rail traction. As a result, an additional reduction of the return line resistance can be achieved with axle counters.

Modern tracks electrified with direct current in order to limit stray currents should meet the requirements of the standard [2] in terms of the unit conductance of the rail-ground transition of a single track. Conductance is the reciprocal of resistance. In the Polish technical nomenclature, the concept of ground rail transition resistance was used. The standard [2] distinguishes only two types of track - open construction - we are dealing here when the entire rails and the structures of the fastening to the ground (sleeper or concrete slab) are visible. 
The second type of track is closed construction - only the running surface of the railhead is visible. This solution occurs at every crossing of the track, i.e. the intersection of the railroad with the highway/road/Pneumatic road. The standard [2] requires that the open track has a unit conductance of the ground rail transition not greater than $0.5 \mathrm{~S} / \mathrm{km}$ (i.e. resistance not less than $2 \Omega \mathrm{km}$ ), while the closed track should have a conductance not greater than $2.5 \mathrm{~S} / \mathrm{km}$ (i.e. resistance not lower than $0.4 \Omega \mathrm{km}$ ) The amendment to the standard [2] of 2011 supplements these requirements with the value of the rail potential in relation to the ground for tracks, respectively $5 \mathrm{~V}$ for the construction of an open and $1 \mathrm{~V}$ for the construction of a closed track. This can be read as a nod to the requirements of the standard [1].

I $\quad \mathrm{n}$ the case of the Polish standard [1], the impact of stray currents was limited at the design level, where for the adopted timetable and the characteristics of the rolling stock intended to run along this section, the power demand of the traction substation was determined and, assuming the no-load voltage in the traction system, the traction current was determined, which, with the knowledge of the selected rails, allows to calculate the drops in the rails of the track with the additional assumption that there has already been $15 \%$ wear of the rail cross-section, and therefore the unit resistance of the new rail increased by this $15 \%$. As a result, the average voltage drop in the rails of the run-out section, which is a railway line, is up to $10 \mathrm{~V}$.

\section{The mechanism of stray currents formation}

The source of stray currents is the voltage drop in the rails of the track. The current in the rails at the vehicle location is equal to the current drawn from the contact wire by the collector. With a two-sided power supply, the current consumption by the vehicle is distributed in proportion to the resistance between the vehicle and these substations. For economic reasons, the catalog selections of the cross-sections of the used return and supply cables as well as the contact wire are selected. The unit weight is related, as in the case of rails, to the unit resistance of the contact wire, but it has a significant impact on the structure and foundation of the pole and the fittings for suspending this wire. The isolation of the overhead network results from two premises: the current leakage from the overhead contact line occurs immediately after the traction voltage is applied to the network and is a loss of energy, similar to the voltage drops in the network occurring during the flow of traction current. The second premise is the electric shock safety of bystanders and the maintenance of the traction system. In order to increase this safety, the railroad poles were individually sewn. The foundation of each pole is a natural earth electrode. From the measurement experience, the resistance of the earth electrodes of the traction poles installed on the tram network in Warsaw ranged from a fraction to almost $200 \Omega$. When poles were sewn individually to the return network, the resultant insulation of the rails from the external ground was reduced. Each pole, depending on its earthling resistance, introduced a local increase in the leakage resistance of the outer rail of the track, the greater the lower the resistance of the earth electrode. Currently, on railway networks, group hardening with the use of low-voltage limiters is used. This solution contributes to the reduction of track leakage during normal operation. Voltage in relation to earth appears on the return network when energy is consumed by the vehicle on the rails of a given network section. The full metallic connections of the rails in the tracks contribute to the possible elevation of the potential of the rails to the adjacent sections connected by return cables to the adjacent substations. This lift is the greater, the smaller the insulation of the adjacent section is (its leakage - the conductance will be greater). 


\section{Estimating stray currents}

The current supplying the vehicle on the trail in the cables and supply lines as well as rails and return cables causes voltage drops, which for economic reasons should be limited in operation, but in the investment process, i.e. design and construction, costs are optimized. In the investment process, assumptions are made that translate into the electrical load during the design of the route, resulting from the route profile, the assumed timetable, and the characteristics of the rolling stock, and this enables the calculation of the average daily, weekly, monthly, quarterly or annual energy consumption. Hence, the substation's power demand is determined. This issue is described in the literature on the subject [3]. As a result, after construction, the operation of the route is usually a double-track route with several possibilities of passing to the adjacent track, which is to enable inspections and repairs along the section and traction substations located approx. Every $20 \mathrm{~km}$, most often supplied from the MV line. In normal operation, the substation will operate on the route on both sides, thanks to which the structure of the substation is repeatable and typical for mains supply. In an emergency, e.g. when there is no power supply from one of the substations, the structure of the DC switching station enables the substation to work as a sectional cabin, thus still ensuring a two-way power supply, but on an extended section. The substations provide protection against failures on the route and in its vicinity, as well as on and in the vicinity of the substations.

After determining the above parameters, you can proceed to the assessment of compliance with the requirements of the standard [1]. Using the long line model for the track system [4], it is possible to derive the formulas for the current distribution in the rails in the ground and the distribution of the rail potential in relation to the ground, assuming the homogeneity (stability) of the electrical parameters of the return network, i.e. unit track resistance rs and unit conductance rail-ground gs this track. Local earth electrodes of traction poles are averaged per section, increasing the unit conductance of the transition, if necessary, or assuming the value required in the standard [2]. From the estimated average energy consumption for a given period of time, the current wrap is determined - that is, the value of the current per supply section resulting from the upper network, evenly distributed [4]. As a rule, a section equal to half the distance between substations is considered [4]. If it is taken into account in the calculations that after exceeding half of the distance between the substations, the work is taken over by the second substation, then with constant parameters, the result of the calculations is shown in Fig. 2. 


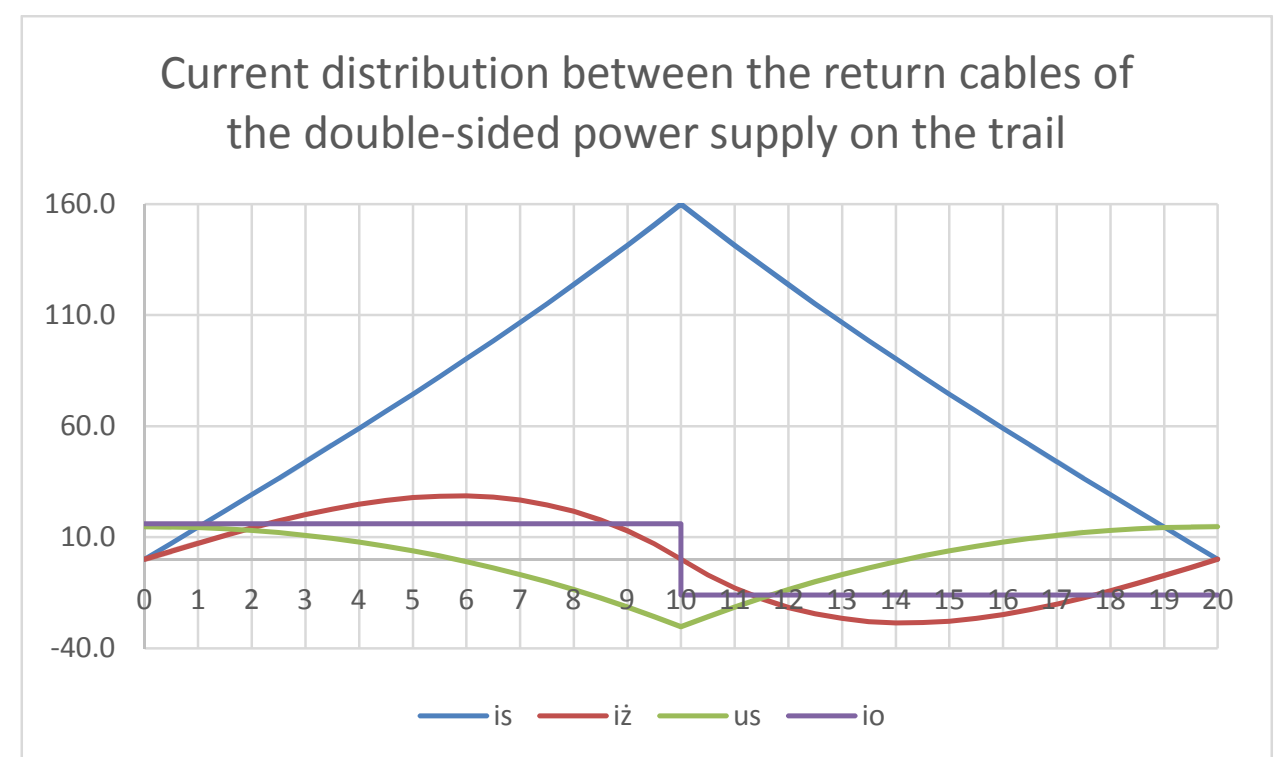

2. Waveforms of busbar current (is), busbar potential (us), and earth current for a section of $2 \mathrm{~L}$ length loaded uniformly on each half with current and between the substation on the left side (return cables at $\mathrm{x}=0$ ) and the substation on the right sides (return cables connected at point $\mathrm{x}=20$ ) Is and io size scale reduced by five times.

Regardless of the assumed values of electrical parameters of the track, its length, and the current supply, the voltage curve us has a characteristic shape, at the return points its positive values are extreme, and in the middle of the distance, it reaches a negative value, usually absolutely greater than the positive values. The conclusions are that, on average, in the vicinity of the return cables on the rails, different phenomena should be expected than in the vicinity of the half of the section between the return cables (substations), if the foundation conditions would be the same and the weather conditions on this section were the same.

The zero value of the potential of the rails in relation to the ground under current loads is a hyperbolic function of the electrical parameters of the track and the length of sections and does not fall out in the halves of half-sections.

\section{Laboratory tests}

In [5], the authors described the results of tests of steel samples in the insulating shell, each of which was equally damaged. Fig. 3 shows a laboratory system in which it can be seen that the samples connected to the DC power supply were in two vessels filled with a $3.5 \%$ saline solution, placed in the same way as the carbon equalizing pipe between these vessels. 


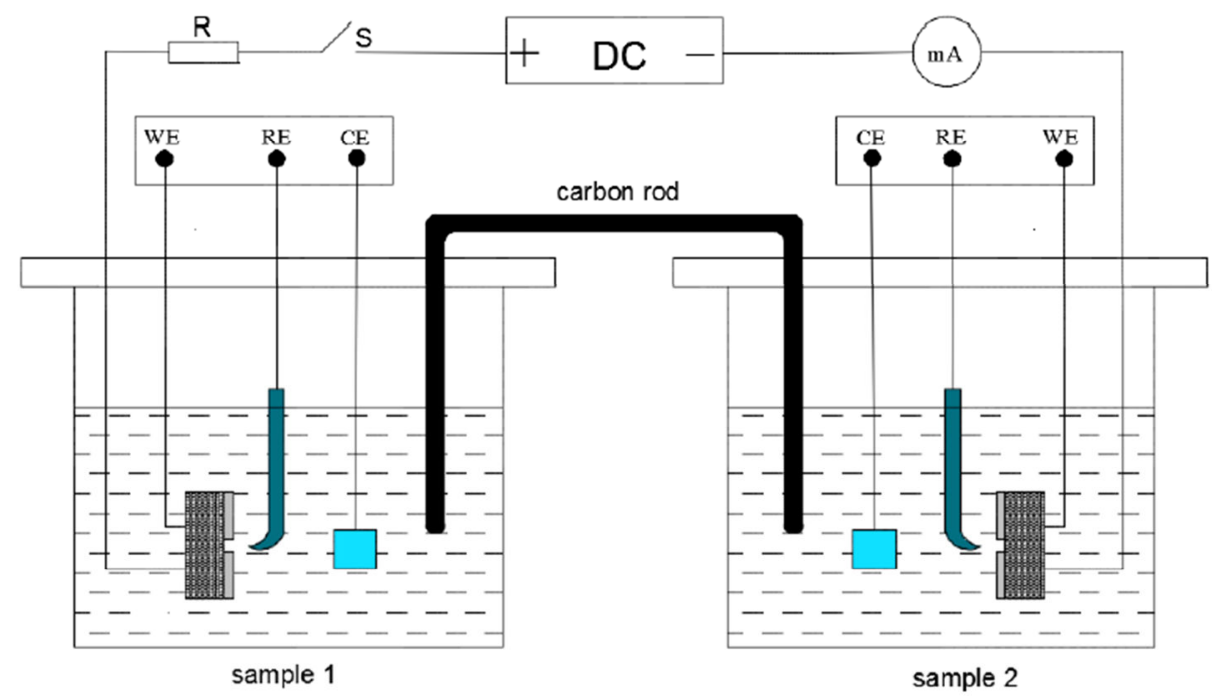

3. Schematic device for direct current (DC) loading during an electrochemical test. WE working electrode; RE -0 reference electrode; CE - counter electrodes; carbon rod - carbon electrode of potential equalization.

In the summary of the results at different values of the current passed through this system during 30 minutes, Fig. 4 shows the characteristic effects of the flow of the electron and ion current to and from the metal. The constant polarization of the source during the tests causes unequivocal damage in the form of pitting on the anode and detachment of the insulation from the metal due to the deposition of electrolyte ions on the metal.
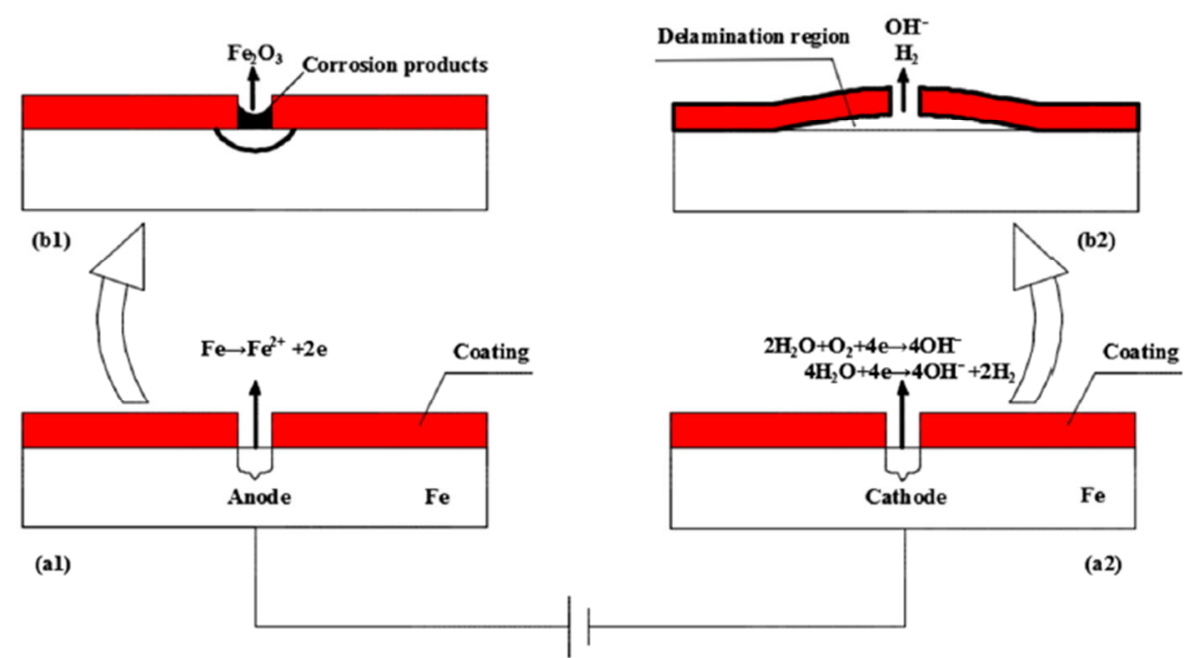

4. The effects of direct current flow through damage to the insulating coatings on steel electrodes, regardless of the current density a 1 and b1 pitting in the anode electrode, a 2 and b2 galvanic deposition of electrolyte ions, and delamination of the insulating coating on the cathode electrode

When comparing the working conditions of the samples and the results of the authors of the work [5], it should be noted that the rails on Polish railway lines sunk in the ballast, which hardly touches the metal surface of the rails, have conditions favorable to corrosive processes only during rainfall, starting from the drizzle, through fine and more intense rain after a downpour and the occurrence of fog or dew point. The persistence of water (diluted electrolyte) on the surface of the rail along the supply section is counteracted by phenomena 
caused by the movement of air over the rails during the passage of trains, as well as the heat generated in the rails from electric energy losses - (square of the current) in the rails and mechanical stresses caused by vehicle axle loads. Moisture can be kept under the rail foot and between the rail foot and the spring washer under the rail, revealing the effect shown in Fig. 5 - see pictures 1 and 2. If the track section with the theoretical anode zone is located in shaded places, e.g. in a forest intersection with short-term sunlight, then there are conditions for keeping moisture for longer in the vicinity of the rail foundation and under the foot of the rails. In the vicinity of the return points, as long as the conditions of the presence of moisture persist for a relatively long time, the application of electrolyte ions on the wet areas of the rails should be expected.

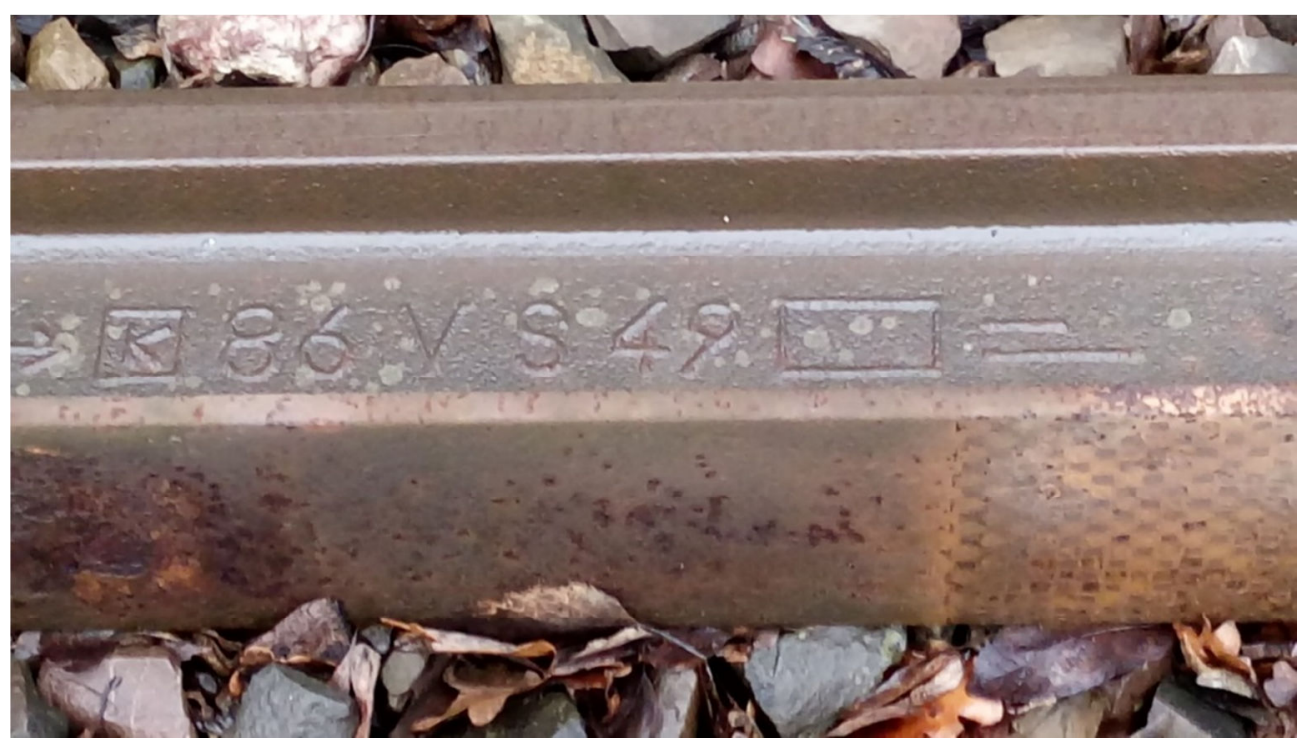

Pic. 1

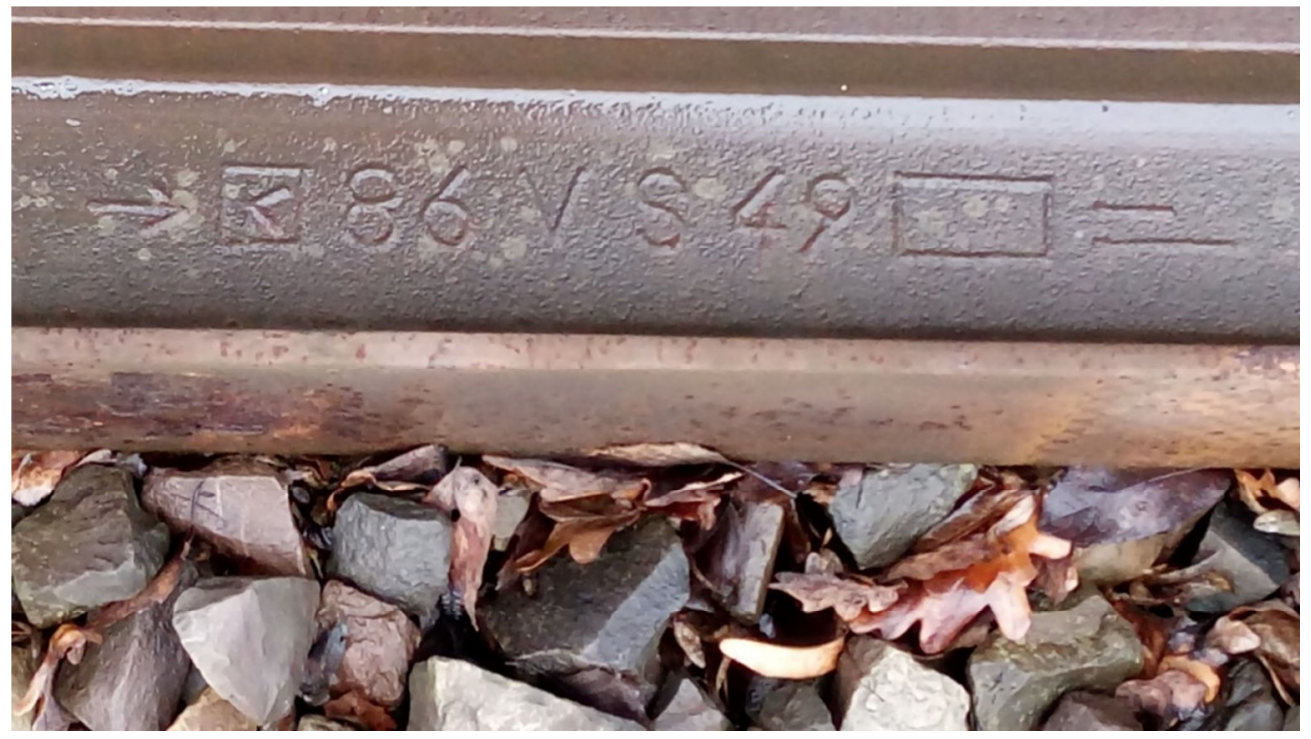

Pic. 2

5. - pictures 1 and 2. Pictures of the foot and side surface of the S49 rails from 1986, taken in January 2020. On the foot on the left side of the picture, you can see corrosive pits to the broken stone in contact with it, and on the right side a pitted imprint of a rail pad. 


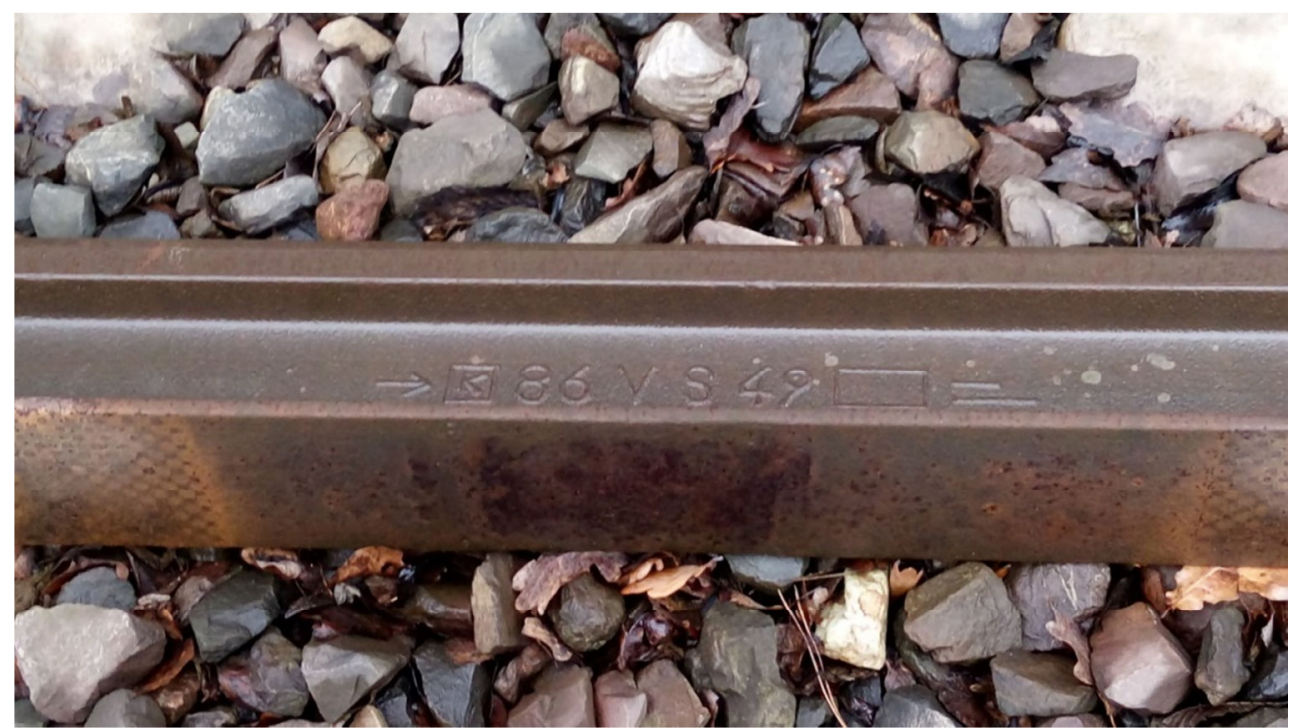

Pic. 3

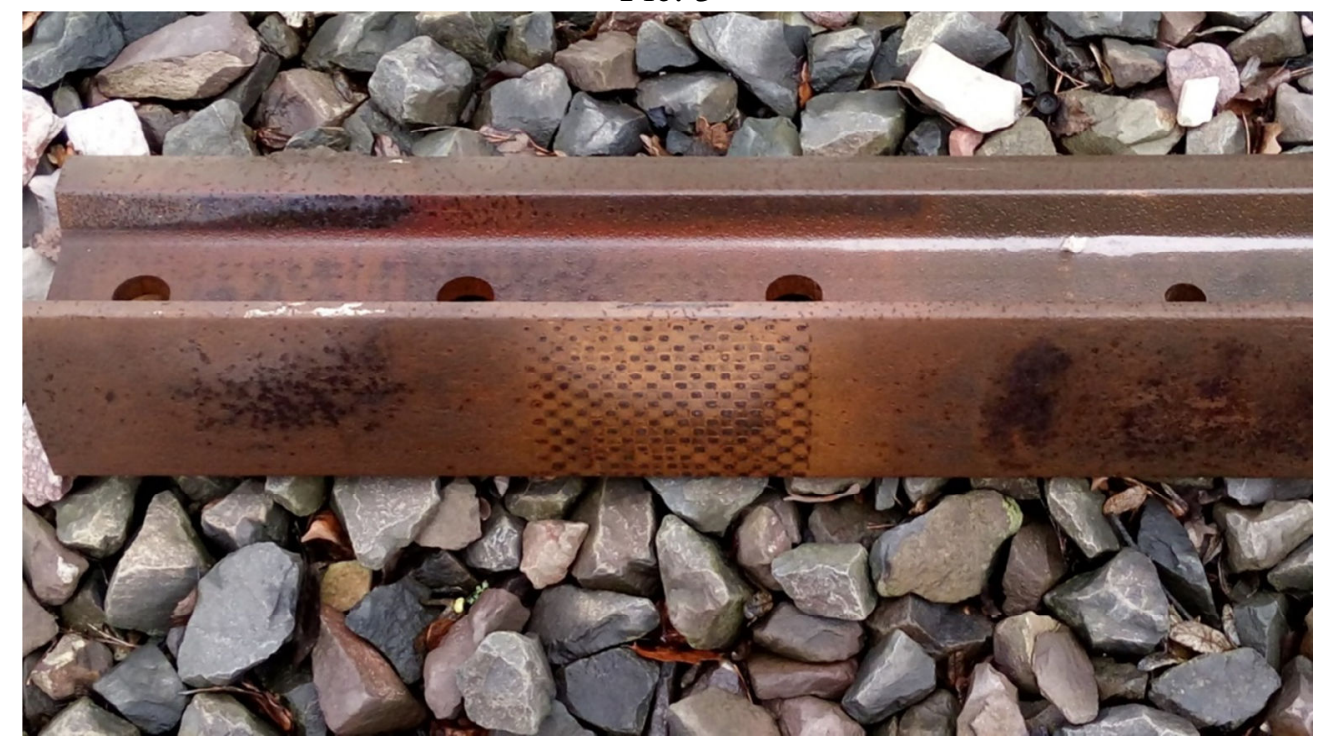

Pic. 4

6. - pictures 3 and 4. Pictures of the feet and side surfaces of the S49 rails from 19. Picture 3 corrosion pits in the foot between the washers, and in picture 4 - the bottom photo - pits in the foot and the point where the rail supports the rail pad at the end of the rail section - the rails are joined with slate, and the corrosion processes in these places are practically invisible. The last hole in the neck of the rail on the right is where the stud of the longitudinal connector of the rails is screwed in.

\section{Remarks on the real influence of stray currents on the corrosion of rails Train journeys through the supply section.}

Table 1 summarizes the times of travel through the section between traction substations on the route if the average or constant speed on this section was from 60 to $200 \mathrm{~km} / \mathrm{h}$. 
Tab. 1. Duration of travel through the section between traction substations on the route

\begin{tabular}{|c|c|c|c|}
\hline $\begin{array}{c}\text { Constant or average } \\
\text { train speed along } \\
\text { section L in km/h }\end{array}$ & \multicolumn{2}{|c|}{ Travel time of the section with the length L } & \multirow{2}{*}{$\begin{array}{c}\text { Average train speed } \\
\text { expressed in } \mathrm{m} / \mathrm{s}\end{array}$} \\
\cline { 2 - 3 } & Seconds & Minutes & 16,7 \\
\hline 60 & 1200 & 20,0 & 22,2 \\
\hline 80 & 900 & 15,0 & 27,8 \\
\hline 100 & 720 & 12,0 & 33,3 \\
\hline 120 & 600 & 10,0 & 38,9 \\
\hline 140 & 514,3 & 8,57 & 44,4 \\
\hline 160 & 450 & 7,5 & 50,0 \\
\hline 180 & 400 & 6,7 & 55,6 \\
\hline 200 & 360 & 6,0 & \\
\hline
\end{tabular}

The railway routes in Poland are still mostly used by locomotives with classic DC drive and starting resistors, the load of which on the route is derived according to the rules given in [6 and 7]. The travel time of the double-sided supply section depends on the driving speed. Shorter times are spent on lighter passenger trains and units of the Dart or Pendolino type. The new and modernized Electric Multiple Units, similarly to the above-mentioned units, have already installed asynchronous drive with a linear increase of the current drawn from the network as the speed is increased to the rated motors installed in these vehicles. In the supply section, each of the trains, especially goods ones, may significantly differ in energy demand. In addition, driving safety requirements cause interruptions in energy consumption from substations. As a result, the instantaneous values of the traction current on the trail are many times greater than it results from the calculations with the use of the current wrap. The current consumption from the two-way power substations is still dependent on the position of the current-collecting vehicle in relation to these substations. For a preliminary engineering estimate, it should be assumed that the same voltage conditions are present at identical substations, which means greater current consumption of currents from the closer form in the proportion resulting from the resistance seen from the traction vehicle "terminals" at a given moment. With the homogeneity of the parameters of the return and supply networks, this proportion comes down to the proportion of the lengths of the sections between the train and the substations. In the point analysis of the current input of the vehicle along the section, the crossing of the bus potential us by zero is always in the middle of the distance between the vehicle and these substations. By analyzing the movement of the train in time along the section of double-sided supply, e.g. with a constant current value, it turns out that the current in the rails in any cross-section will change the sign of the flow, and the duration of the current flow in one direction is a function of the speed of the train and the distance of this section from the substation. In these considerations, the transient states of changes resulting from the relatively point current consumption of the contact wire as compared to the multipoint contact of the wheel rims of all vehicle axles have been ignored. These axles are spread over trolleys along with the depot with a length of up to several hundred meters. In addition, there are changes in the load of the current drawn from the network during start-up as a result of switching the starting resistance values in a classic drive with DC motors, or the increase in the network current with an increase in the speed of the composition in accordance with the electronically set characteristics of the vehicle start-up process. It is almost impossible for all trains to pass through half of the supply section on the supply section without drawing traction current, including their own needs. Therefore, for any long observation period compared to the design daily, weekly, monthly, quarterly, or yearly averages, the resultant averaged potential distribution along the supply section will be close to that shown in Fig. 2. In fact, on a route in a DC electrified rail system, corrosion of rails can only occur under unfavorable 
conditions of permanent water presence under the rail foot. Corrosion processes in the presence of moisture are variable (the effects of alternating current), which is caused by the movement and local consumption of traction current by vehicles on the trail. It is difficult to determine the periodicity, let alone the amplitude of changes over time, in the variability of the current consumption in the supply section of the railway line. These factors mean that the negative effects in the form of pits in the rail material on open construction track tracks are minimal, despite the presence of larger currents in the ground or greater potential of the rails compared to tram tracks or metro tracks [4].

\section{Source materials}

[1] PN-92/E-05024 Ochrona przed korozją. Ograniczenie upływu prądów z trakcyjnych sieci powrotnych prądu stałego

[2] PN EN 50122-2: Zastosowania kolejowe Urządzenia stacjonarne. Część 2 Środki ochrony przed oddziaływaniem prądów błądzących wywołanych przez trakcję elektryczną

[3] Mierzejewski L., Szeląg A., Gałuszewski M.: System zasilania trakcji elektrycznej prądu stałego Skrypt Politechniki Warszawskiej Warszawa 1989

[4] Dziuba W.: Sieć powrotna i prądy błądzące Wyd. Książkowe IEl Seria A Prace orginalne

[5] Xinhua Wang i in. Effect of a DC Stray Current on the Corrosion of X80 Pipeline Steel and the Cathodic Disbondment Behavior of the Protective 3PE Coating in 3.5\% $\mathrm{NaCl}$ Solution Coatings 2019, 9, 29; doi:10.3390/coatings9010029

[6] Podowski J. Zasady trakcji elektrycznej WKiŁ 1967

[7] Podowski J., Kacprzak J., Mysłek J.: Zasady trakcji elektrycznej WKŁ 1980 